OPTIMAL DEMOGRANTS AND TAXES IN A

FEDERAL WELFARE STATE

by

Ranjan Ray

DISCUSSION PAPER 92.08

ISSN 0811-6067

ISBN 0-86422-190-8 
OPTIMAL DEMOGRANTS AND TAXES IN A FEDERAL WELFARE STATE

by

Ranjan Ray

DISCUSSION PAPER 92.08 


\section{OPTIMAL DEMOGRANTS AND TAXES IN A FEDERAL WELFARE STATE*}

by

\section{Ranjan Ray}

Department of Economics

Delhi School of Economics

Delhi University

Delhi-110007

India

Written: June, 1991

Revised: May, 1992

*Much of the work in this paper was done during my visit to the Scuola Superiore, S. Anna in Pisa (Italy) in the summer of 1991. The paper was revised during my visit to the Economic Research Centre, University of Western Australia, during May/June 1992. I am grateful to the staff and students of both institutions for their hospitality. I also thank two anonymous referees for helpful remarks. The disclaimer applies. 


\begin{abstract}
This paper provides a framework for the simultaneous calculation of optimal commodity and income taxes in a federal framework with demogrants. The optimal income tax rate is shown to depend on a range of demographic and economic variables. Alternative models of fiscal federalism are proposed, and their implications for optimal commodity taxes and demogrants considered. Illustrative empirical evidence on Indian data confirms sensitivity of tax magnitudes to federal specification, and to assumptions about resource transfer between the federal and provincial authorities.
\end{abstract}




\section{Introduction}

Traditionally, optimal tax models, be it income or commodity tax, assume an unitary form of government with an exclusive right to design and levy taxes ${ }^{1 /}$. Exceptions include Arnott and Grieson (1981), Gordon (1983), Wildasin (1984), Mintz and Tulkens (1986) - see also Oates (1990) for a discussion of some of the wider issues in 'fiscal federalism'. The traditional models seem ill suited for federal countries. e.g. Australia, Canada, India and the U.S.A. The typical federal characteristics include: (i) many levels of government each with a constitutional right to levy taxes, partly on the same base, (ii) statutory definition of some taxes (namely, income tax and the excise component of commodity tax) as federal instruments, while others (namely the 'sales tax') belong to the provinces $2 /$ and (iii) resource transfer from the federal government to the constituent provinces of the federal Union. The main virtue of fiscal federalism is the freedom of provincial governments to take economic decisions, keeping in mind local needs and resource constraints. The provincial authorities independently determine their revenue requirements and may also like to consider the demand preferences of regional population in designing 'sales taxes'. In contrast, the federal authority designs income and 'excise' taxes given national economic objectives (e.g. clefence expenditure) and to secure economic redistribution between the provinces. A distinctive characteristic of a federal nation, often overlooked in the traditional optimal tax literature, is the ability of federal and provincial governments to alter each other's tax base by unilaterally using their respective tax instruments. Another fiscal characteristic with implication for the optimal tax calculations is the presence of resource transfer from the federal government to the constituent provinces. The generalised tax formulae and the empirical evidence, presented later, show that the resource transfer parameter exerts a significant impact on the structure of optimal taxes.

Another significant limitation of the traditional optimal tax literature has been the absence of a unified analytical framework for the simultaneous calculation of optimal commodity and income taxes. The literature on optimal income tax has grown, in parallel with that on optimal commodity taxes, but there has been relatively little interaction between the two. Following Mirrlees (1971), the optimal income tax literature typically assumes away commodity taxes [see, for example, Stern (1976), Tuomala (1984)], while the optimal commodty tax literature similarly assumes that the entire revenue requirement is met through commodity taxes [see, for example, Ray (1986, 1988)]. Dixit and Sandmo (1977), after noting the reasons for the rela.tively little interaction between the two parallel developments in the optimal tax literature, pointed out the similarity between the equity/efficiency trade off in the 
optimal income tax formulation and in the many person generalisation of the Ramsey result on optimal commodity taxes discussed by, for example, Diamond (1975). Dixit and Sandmo (1977)'s optimal tax formulae are derived, however, under the traditional assumption of no commodity taxes. An important characteristic of social security and tax systems in many countries, especially the developed economies, is the presence of demogrants linked to household composition. It is not widely appreciated that such payments also have important implications for optimal taxes.

The motivation of this paper is the presentation of an appropriate theoretical framework that allows analysis and calculation of optimal demogrants, income ${ }^{3 /}$ and commodity taxes in a federal set up. The paper presents alternative approaches to the study of optimal taxation in a federal set-up based on centralised and decentralised models of fiscal federalism. In the former, the federal and provincial tax and spending behaviour are fully co-ordinated so that the centralised model captures the external effects of changes in federal, provincial taxes on the resource of the other. In contrast, in the decentralised procedure, each decision making unit acts independently, in the light ot its own objectives, taking as given the fiscal decisions made by the others. As this paper shows, both the quantitative and the qualitative conclusions about the structure of optimal commodity taxes vary quite significantly between the alternative federal models.

The plan of this paper is as follows. The centralised variant of the federal tax model with demogrants is presented, and some propositions on 'optimal demogrants' and the optimal income tax formula in the presence of commodity taxes are derived in Section II. The implication of federal to provincial resource transfers for the optimal income tax is discussed in Section III. The decentralised model of fiscal federalism is presented and the consequence of optimal demogrants in such a set up is examined in Section IV. Section V analyses the implication of optimal commodity taxes under the altemative variants of fiscal federalism, and presents analytical and empirical evidence that confirm sensitivity of tax rules and tax estimates to federal specification. The paper ends on the concluding note of Section VI. 


\section{The Centralised Federal Tax Model with Demogrants and Demographic Variables}

Let $v_{h}^{j}\left(p^{j}, w_{h}^{j}, c_{h}^{j}, M_{h}^{j}\right)$ denote the indirect utility function of household $h(=1, \ldots, H)$ in province $j(=1, \ldots, J) . p^{j}, w_{h}^{j}, c_{h}^{j} 4 /$ denote, respectively, the commodity price vector (assumed identical across households within a province), the gross wage rate and the number of children of household $h$ in province $j . M_{h}^{j}=w_{h}^{j}(1-\tau) L_{h}^{j}$ is the net wage income ${ }^{5 /}$ of household $h, L_{h}$ is labour supplied and $\tau$ is the rate of income tax (assumed constant). Households differ, therefore, not only in their preferences, denoted by $v_{h}(\cdot)$, but also in their household composition and skills denoted by $c_{h}, w_{h}$ respectively. Let $x_{h}^{j}$ denote the vector of commodity demand. Note that following the household utility function approach adopted here, [see Barten (1964), Pollak and Wales (1981), Ray (1988)], commodity demand will be functions of, beside prices, gross wage rate, income and commodity tax rates, and demographic variables.

The social welfare $\psi$ of the nation is defined over the social welfare $W^{j}$ of the provinces which, in turn, are defined over the resident households' indirect utilities.

$$
\psi(p, w, c, M)=\psi\left[W^{1}\left\{v^{1}\left(p^{1}, w^{1}, c^{1}, M^{1}\right)\right\}, \ldots, W^{J}\left\{v^{J}\left(p^{J}, w^{J}, c^{J}, M^{J}\right)\right\}\right]
$$

where $v^{j}(\cdot)$ is the vector of utilities of residents in province $j$, and $w^{j}, c^{j}, M^{j}$ the corresponding vectors of gross wage rates, number of children and wage income, respectively. The subvectors $p^{j}(j=1, \ldots, J)$ constitute the $(J n \times 1)$ aggregate price vector $p$, and $w, c, M$ are the corresponding vectors of wages $(J H \times 1)$, children $(J H \times 1)$ and aggregate expenditure $(J H \times 1)$ for all the households in the federal nation. Note that, for analytical simplicity, we assume that there are an identical number of households in each province.

Assuming full shifting of taxes, as is traditional in the literature, the consumer price has three elements

$$
p_{i}^{j}=\bar{p}_{i}+\theta_{i}+t_{i}^{j}
$$

$$
j=1, \ldots, J
$$

where $\theta_{i}$ is the 'excise tax' on commodity $i$ set and collected by the federal authorities, $t_{i}^{j}$ is the province-specific 'sales tax' and, without loss of generality, the producer price $\bar{p}_{i}$ is assumed to be constant across provinces. Assuming a linear income tax (i.e. constant marginal tax rate $\tau$ ) set and collected by the federal authority, let $w_{h}^{j *}=w_{h}^{j}(1-\tau)$ deonte the net wage rate of household $h$ in province $j$.

Each household, besides paying income and commodity taxes, receives a demogrant $g_{h}^{j}(\cdot)$ consisting of a uniform payment of $\gamma_{0}$ from the federal authority, and 
a province-specific child subsidy at the rate of $\gamma_{1 h}^{j}$ per child. Hence

$$
g_{h}^{j}=\gamma_{0}+\gamma_{1 h}^{j}\left(w_{h}^{j}\right) c_{h}^{j}
$$

We choose the following functional form for $\gamma_{1 h}^{j}$ :

$$
\gamma_{1 h}^{j}=\bar{\gamma}_{1} e^{\bar{\gamma}_{1}^{j} w_{h}^{j}}
$$

While the parameter $\bar{\gamma}_{1}$, which is invariant across the provinces, is set by the federal government, $\tilde{\gamma}_{1}^{j}$, set by the provincial authorities, allows the child subsidy rate to vary with household shills measured by $w_{h}^{j} 6 /$.

The federal policy parameters are therefore $\left\{\gamma_{0}, \bar{\gamma}_{1}, \theta_{i}, \tau\right\}$ while those of the provinces are given by $\left\{\tilde{\gamma}_{1}^{j}, t_{i}^{j}\right\}, j=1, \ldots, J, i=1, \ldots, n$. Assuming what Gordon (1983, p 573) calls 'fully co-ordinated decision making behaviour' between the federal and provincial authorities, the optimal demogrant/tax problem involves choosing the policy parameters $\left\{\bar{\gamma}_{0}, \bar{\gamma}_{1}, \tilde{\gamma}_{1}^{j}, \theta_{i}, t_{i}^{j}, \tau\right\}$ so as to maximise the nation's social welfare function $\psi(p, w, c, M)$ subject to the following federal and provincial resource constraints.

$$
\begin{gathered}
R^{o} \leq \sum_{h} \sum_{i} \sum_{j} \theta_{i} x_{i h}^{j}+\sum_{h} \sum_{j} \tau w_{h}^{j} L_{h}^{j}-J H \gamma_{0} \\
R^{j} \leq \sum_{h} \sum_{i} t_{i}^{j} x_{i h}^{j}-\sum_{h} \gamma_{1 h}^{j}\left(w_{h}\right) c_{h}^{j}
\end{gathered}
$$

$$
j=1, \ldots, J
$$

$R^{0}, R^{1}, \ldots, R^{J}$ are, respectively, the net revenue requirements of the Union and the constituent provinces. In this section, we discuss the optimal demogrants and income $\operatorname{tax}\left(\gamma_{0}, \bar{\gamma}_{1}, \tau\right)$ in the centralised federal set up. As already mentioned, the issue of optimal commodity taxes $\left(\theta_{i}, t_{i}^{j}\right)$ is discussed in Section V.

The exercise implies the following Lagrangean

$$
\begin{aligned}
\tilde{L}=\psi(p, w, c, M) & +\lambda\left[\sum_{j} \sum_{h} \sum_{i} \theta_{i} x_{i h}^{j}+\sum_{h} \sum_{j} \tau w_{h}^{j} L_{h}^{j}-J H \gamma_{0}-R^{0}\right] \\
& +\sum_{j=1}^{J} \mu^{j}\left(\sum_{h} \sum_{i} t_{i}^{j} x_{i h}^{j}-\sum_{h} \gamma_{1 h}^{j} c_{h}^{j}-R^{j}\right)
\end{aligned}
$$

where the Lagrange multipliers $\lambda, \mu^{1}, \mu^{2}, \ldots, \mu^{J}$ can be interpreted as the marginal 'social' cost of raising an extra unit of revenue by the federal and provincial authorities, respectively. 
marginal utility of income of household $h$ in province $j$ to the nation as a whole (measured in terms of the federal revenue constraint multiplier $\lambda$ as numeraire), after allowing for commodity and income taxes accruing from the incremental unit of income/expenditure. The conditions for 'optimal demogrants' [equations ( $7 \mathrm{a})-(7 \mathrm{c})$ ] can be re-written, in terms of $b_{h}^{j}$, as follows:

$$
\begin{aligned}
\bar{b} \equiv & \frac{1}{J H} \sum_{h} \sum_{j} b_{h}^{j}=1 \\
& \sum_{j} \sum_{h}\left(b_{h}^{j}-\frac{\mu^{j}}{\lambda}\right) e^{\bar{\gamma}_{1}^{j} w_{h}^{j}} c_{h}^{j}=0 \\
& \sum_{h} b_{h}^{j} e^{\tilde{\gamma}_{1}^{j} u_{h}^{j}} c_{h}^{j} w_{h}^{j}=\frac{\mu^{j}}{\lambda} \sum_{h} e^{\tilde{\gamma}_{1}^{j} w_{h}^{j}} c_{h}^{j} w_{h}^{j}
\end{aligned}
$$

$$
j=1, \ldots, J
$$

To interpret these optimality conditions, let us rewrite (9b), (9c) as follows

$$
\begin{aligned}
\lambda & =\sum_{j} \sum_{h} \phi_{h}^{j 1} \mu^{j} \\
\frac{\mu^{j}}{\lambda} & =\sum_{h} \phi_{h}^{j 2} b_{h}^{j}
\end{aligned}
$$

$$
j=1, \ldots, J
$$

where

$$
\phi_{h}^{j 1}=\frac{e^{\bar{\gamma}_{1}^{j} w_{h}^{j}} c_{h}^{j}}{\sum_{j} \sum_{h} b_{h}^{j} e^{\bar{\gamma}_{1}^{j} w_{h}^{j}} c_{h}^{j}}, \quad \phi_{h}^{j 2}=\frac{e^{\bar{\gamma}_{1}^{j} w_{h}^{j}} c_{h}^{j} w_{h}^{j}}{\sum_{h} e^{\bar{\gamma}_{1}^{j} w_{h}^{j}} c_{h}^{j} w_{h}^{j}}
$$

Condition (9a) states that if the demogrant scheme is 'optimal' then the mean of the net social marginal utility of income over all the households in the nation must equal unity - in other words, demogrants simply act like the lump sum subsidy component of an optimal linear income tax scheme [see Atkinson and Stinglitz (1980, pgs 407408)]. Conditions (10), (11) state the relationships between the marginal social costs of raising revenue by the federal and provincial authorities that must be satisfied if the federal and provincial demogrant schemes are both optimal. Note, incidentally, that (9c) implies

$$
\sum_{h}\left(b_{h}^{j}-\frac{\mu^{j}}{\lambda}\right) e^{\tilde{\gamma}_{1}^{j} w_{h}^{j}} c_{h}^{j} w_{h}^{j}=0
$$

$$
j=1, \ldots, J
$$


Assuming that all the demand and welfare functions are well behaved and that the regularity conditions are satisfied, the optimal values of the demogrant parameters $\left\{\gamma_{0}, \bar{\gamma}_{1}, \tilde{\gamma}_{1}^{j}\right\}$ imply, respectively, the following first order conditions. ${ }^{7 /}$

$$
\begin{aligned}
& 0=\frac{\delta \tilde{L}}{\delta \gamma_{0}} \equiv \sum_{j} \sum_{h} \frac{\delta \psi}{\delta W^{j}} \frac{\delta W^{j}}{\delta v_{h}^{j}} \frac{\delta v_{h}^{j}}{\delta M_{h}} \\
& +\lambda\left[\sum_{j} \sum_{h} \sum_{i} \theta_{i} \frac{\delta x_{i h}^{j}}{\delta M_{h}^{j}}+\tau \sum_{j} \sum_{h} w_{h}^{j} \frac{\delta L_{h}^{j}}{\delta M_{h}^{j}}-J H\right] \\
& +\sum_{j} \mu^{j}\left[\sum_{i} \sum_{h} t_{i}^{j} \frac{\delta x_{i h}^{j}}{\delta M_{h}^{j}}\right] \\
& 0=\frac{\delta \tilde{L}}{\delta \bar{\gamma}_{1}} \equiv \sum_{j} \sum_{h} \frac{\delta \psi}{\delta W^{j}} \frac{\delta W^{j}}{\delta v_{h}^{j}} \frac{\delta v_{h}^{j}}{\delta M_{h}^{j}} e^{\bar{\gamma}_{1}^{j} w_{h}^{j}} c_{h}^{j} \\
& +\lambda \sum_{j} \sum_{h}\left(\sum_{i} \theta_{i} \frac{\delta x_{i h}^{j}}{\delta M_{h}^{j}}+\tau w_{h}^{j} \frac{\delta L_{h}^{j}}{\delta M_{h}^{j}}\right) e^{\tilde{\gamma}_{1}^{j} w_{h}^{j}} c_{h}^{j} \\
& +\sum_{j} \sum_{h} \mu^{j}\left(\sum_{i} t_{i}^{j} \frac{\delta x_{i h}^{j}}{\delta M_{h}^{j}}-1\right) e^{\bar{\gamma}_{1}^{j} w_{h}^{j}} c_{h}^{j} \\
& 0=\frac{\delta \tilde{L}}{\delta \tilde{\gamma}_{1}^{j}}=\sum_{h} \frac{\delta \psi}{\delta W^{j}} \frac{\delta W^{j}}{\delta v_{h}^{j}} \frac{\delta v_{h}^{j}}{\delta M_{h}^{j}} \bar{\gamma}_{1} e^{\bar{\gamma}_{1}^{j} w_{h}^{j}} w_{h}^{j} c_{h}^{j} \\
& +\lambda \sum_{h}\left(\sum_{i} \theta_{i} \frac{\delta x_{i h}^{j}}{\delta M_{h}^{j}}+\tau w_{h}^{j} \frac{\delta L_{h}^{j}}{\delta M_{h}^{j}}\right) \bar{\gamma}_{1} e^{\tilde{\gamma}_{1}^{j} w_{h}^{j}} w_{h}^{j} c_{h}^{j} \\
& +\mu^{j} \sum_{h}\left(\sum_{i} t_{i}^{j} \frac{\delta x_{i h}^{j}}{\delta M_{h}^{j}}-1\right) \bar{\gamma}_{1} e^{\bar{\gamma}_{1}^{j} w_{h}^{j}} w_{h}^{j} c_{h}^{j}
\end{aligned}
$$

$$
j=1, \ldots, J
$$

Denoting $\beta_{h}^{j}=\frac{\delta W^{j}}{\delta M_{h}^{j}}$ to be the 'social marginal utitlity of income' of household $h$ in province $j$ to that province's authority, let us define

$$
b_{h}^{j}=\frac{\delta \psi}{\delta W^{j}} \frac{\beta_{h}^{j}}{\lambda}+\sum_{i}\left(\theta_{i}+\frac{\mu^{j}}{\lambda} t_{i}^{j}\right) \frac{\delta x_{i h}^{j}}{\delta M_{h}^{j}}+\tau w_{h}^{j} \frac{\delta L_{h}^{j}}{\delta M_{h}^{j}}
$$

$b_{h}^{j}$, which depends not only on the planner's distributive values within the province via $\beta_{h}^{j}$ but also across the provinces via $\frac{\delta \psi}{\delta W^{j}}$ can be interpreted as the net social 
Since $e^{\bar{\gamma}_{1}^{j} w_{h}^{j}}>0, c_{h}^{j} \geq 0, w_{h}^{j}>0,(12)$ implies that

$$
b_{h}^{j}(\min )<\frac{\mu^{j}}{\lambda}<b_{h}^{j}(\max )
$$

(13) provides the range within which $\frac{\mu^{j}}{\lambda}$ must lie if the demogrant scheme in province $j$ is optimal. The above discussion can be summarised in the following Proposition.

Proposition I: Within the federal/provincial child subsidy schemes, given by equations (3), (4), if the demogrants are optimal, then (i) the unweighted mean of the net social marginal utility of income of the nation must equal unity, (ii) relationships (10), (11) between the federal and provincial resource constraint multipliers must be satisfied, and (iii) as a consequence of (ii), the marginal social cost of raising revenue in a province, relative to that in the federal Union, must lie between the minimum and maximum values of the net social marginal utility of income in that province.

As a corollary of the above proposition, note that for every province, the ratio $\left(\frac{\mu^{j}}{\lambda}\right)$ is simply a weighted average of the $b_{h}^{j} \mathrm{~s}$ of the individual households, with the weights $\phi_{h}^{j 2}$ incorporating the demographic and wage distribution in that province.

The optimal value of the income tax rate $\tau$ implies the following first order conclition

$$
\begin{aligned}
0=\frac{\delta \tilde{L}}{\delta \tau} \equiv \sum_{j} \sum_{h} \frac{\delta \psi}{\delta W^{j}} \frac{\delta W^{j}}{\delta v_{h}^{j}} \frac{\delta v_{h}^{j}}{\delta \tau} \\
+\lambda\left[\sum_{j} \sum_{h} \sum_{i} \theta_{i} \frac{\delta x_{i h}^{j}}{\delta M_{h}^{j}}\left\{-w_{h}^{j} L_{h}^{j}+(1-\tau) w_{h}^{j} \frac{\delta L_{h}^{j}}{\delta \tau}\right\}\right. \\
\left.+\sum_{j} \sum_{h}\left(L_{h}^{j}+\tau \frac{\delta L_{h}^{j}}{\delta \tau}\right) w_{h}^{j}\right] \\
+\sum_{j} \mu^{j}\left[\sum_{j} \sum_{i} t_{i}^{j} \frac{\delta x_{i h}^{j}}{\delta M_{h}^{j}}\left\{-w_{h}^{j} L_{h}^{j}+(1-\tau) w_{h}^{j} \frac{\delta L_{h}^{j}}{\delta \tau}\right\}\right]
\end{aligned}
$$

Using the Slutsly decomposition

$$
\frac{\delta L_{h}^{j}}{\delta \tau}=-w_{h}^{j} S_{L L, h}^{j}-w_{h}^{j} L_{h}^{j} \frac{\delta L_{h}^{j}}{\delta M_{h}^{j}}
$$

where $S_{L L}$ is the non-negative Slutsky substitution term (compensated response of labour to the marginal net wage), (14) yields, after some re-arrangement

$$
\frac{\tau}{1-\tau}=\frac{1}{\sum_{j} \sum_{h} Z_{h}^{j} \rho_{h}^{j} \epsilon_{L L, h}^{j}}[-\operatorname{Cov}(b, Z)+(\tau-1) D]
$$


where $Z_{h}^{j}=w_{h}^{j} L_{h}^{j}$ is gross earnings, and defining $\tilde{t}_{i}^{j}=\theta_{i}+\left(\frac{\mu^{j}}{\lambda}\right) t_{i}^{j}$

$$
\begin{aligned}
& \rho_{h}^{j}=1+\left(\frac{1-\tau}{\tau}\right) \sum_{i} \tilde{t}_{i}^{j} \frac{\delta x_{i h}^{j}}{\delta M_{h}^{j}} \\
& D=\sum_{j} \sum_{h} \sum_{i} \tilde{t}_{i}^{j} \frac{\delta x_{i h}^{j}}{\delta M_{h}^{j}} \frac{\delta L_{h}^{j}}{\delta M_{h}^{j}} w_{h}^{j} Z_{h}^{j}
\end{aligned}
$$

$\operatorname{Cov}(b, Z)=\sum_{j} \sum_{h}\left(b_{h}^{j}-\tilde{b}\right) Z_{h}^{j}$ is the covariance between the net social marginal utility of incone and gross earnings for the nation as a whole and $\epsilon_{L L, h}^{j}$ is the compensated wage elasticity $\left[\frac{w_{h}^{j}(1-\tau)}{L_{h}^{j}} S_{L L, h}^{j}\right]$. Note that (16) generalises the standard optimal income tax formula [see Atkinson and Stiglitz (1980, p. 407)] to the federal country case with demogrants and commodity taxes. The reader can easily verify that if provincial and federal taxes are proportional across items with the constant of proportionality being given by $\left(-\frac{\mu^{j}}{\lambda}\right)$, or, in other words, if $\tilde{t}_{i}^{j}=0$ then (16) gives the traditional optimal income tax rate formula. Equation (16) yields, on further re-arrangement, a more direct expression for the optimal income tax rate $\tau$.

$$
\begin{gathered}
\operatorname{Cov}(b, Z)+\sum_{j} \sum_{h} \sum_{i} \tilde{t}_{i}^{j} \frac{\delta x_{i h}^{j}}{\delta M_{h}^{j}} Z_{h}^{j} \epsilon_{L L, h}^{j} \\
\sum_{j} \sum_{h} \sum_{i} \tilde{t}_{i}^{j} e_{i h}^{j} e_{L h}^{j} x_{i h}^{j} \\
\operatorname{Cov}(b, Z)+\sum_{j} \sum_{h} \sum_{i} \tilde{t}_{i}^{j} \frac{\delta x_{i h}^{j}}{\delta M_{h}^{j}} Z_{h}^{j} \epsilon_{L L, h}^{j}-\sum_{j} \sum_{h} Z_{h}^{j} \epsilon_{L L, h}^{j}
\end{gathered}
$$

$e_{i h}^{j}=\frac{\delta x_{i h}^{j}}{\delta M_{h}^{j}} \frac{M_{h}^{j}}{x_{i h}^{j}}$ and $e_{L h}^{j}=\frac{\delta L_{h}^{j}}{\delta M_{h}^{j}} \frac{M_{h}^{j}}{L_{h}^{j}}$ denote the income elasticities of commodity $i$ and labour, respectively. Note that (19) is not an explicit expression for the optimal income tax rate $\tau$, since $\tau$ enters the r.h.s. via the income derivatives and the various elasticities. (19) can be, alternatively, expressed as

$$
\tau=\frac{\operatorname{Cov}(b, Z)+\sum_{j} \sum_{h} \sum_{i}\left[\frac{\delta x_{i h}^{j}}{\delta M_{h}^{j}} Z_{h}^{j} \epsilon_{L L, h}^{j}+e_{i h}^{j} e_{L h}^{j} x_{i h}^{j}\right] \tilde{t}_{i}^{j}}{\operatorname{Cov}(b, Z)+\sum_{j} \sum_{h}\left[\sum_{i} \tilde{t}_{i}^{j} \frac{\delta x_{i h}^{j}}{\delta M_{h}^{j}}-1\right] Z_{h}^{j} \epsilon_{L L, h}^{j}}
$$

There is considerable controversy in the literature about the magnitude of the optimal marginal income tax rate $\tau$. It depends on, among others, the provincial, federal 
commodity taxes $\left(t_{i}^{j}, \theta_{i}\right)$, on their corresponding resource costs $\left(\mu^{j}, \lambda\right)$, and on the wage and demographic distribution of households. $\tau$ further depends not only on the compensated wage elasticities $\left(\in_{L L}\right)$, as the literature suggests, but also on the demand elasticities as well. Equation (20) suggests that it is misleading to study, as Stern (1976) does, the relationship between the optimal income tax rate $\tau$ and the elasticity of substitution between goods and leisure, without taking into account the commodity composition of household expenditure, the commodity tax rates, and the disaggregated demand derivatives with respect to income. It is interesting to note from (20) that, unlike in the traditional unitary State formulation, $\operatorname{Cov}(b, Z)=0$ does not necessarily imply that the optimal marginal income tax rate $(\tau)$ is zero as well. Following Atkinson and Stiglitz (1980, p. 408) who interpret $\operatorname{Cov}(b, Z)$ as a. measure of inequality, this implication of optimal income tax formulation in the federal case represents a distinct break with the traditional literature, and suggests that our intuition need not always be correct. (20) further implies that, in yet another break with the traditional case, a perfectly inelastic compensated supply curve for labour (i.e. $\epsilon_{L L}^{h}=0$ ) is quite consistent with non unitary optimal income tax rate $(\tau \neq 1)$. The reason for this is the presence of commodity taxes which, as already noted, causes the commodity demand derivatives to be an important determinant of $\tau$.

\section{Optimal Income Tax in the Presence of Resource Transfer}

A significant characterisitic of a federal structure is the presence of resource transfer from the federal Union to the provinces. The federal tax model, introduced above, can be easily extended to include such transfer. We assume, keeping in mind the case of India, that a portion $(s)$ of the income tax receipts, accruing to the 'Centre', is returned to the provinces. Let $s^{k}$ denote the share of province $k$, as a proportion of total income tax revenue, of the resource transfer so that $s=\sum_{k=1}^{J} s^{k}$. The $s^{k} s$, which in India are fixed periodically by the Finance Commissions, are considered exogenous in this paper. In the extended model, the revenue constraints become

$$
\begin{aligned}
& R^{0} \leq \sum_{h} \sum_{i} \sum_{j} \theta_{i} x_{i h}^{j}+(1-s) \sum_{h} \sum_{j} \tau w_{h}^{j} L_{h}^{j}-J H \gamma_{0} \\
& R^{j} \leq \sum_{h} \sum_{i} t_{i}^{j} x_{i h}^{j}+s^{j} \sum_{h} \sum_{k} \tau w_{h}^{k} L_{h}^{k}-\sum_{h} \gamma_{1 h}^{j}\left(c_{h}^{j}\right) c_{h}^{j}
\end{aligned}
$$

$j=1, \ldots, J$ 
The extended Lagrangean is, thus, as follows.

$$
\begin{aligned}
\tilde{L} & =\psi(p, w, c, M)+\lambda\left[\sum_{j} \sum_{h} \sum_{i} \theta_{i} x_{i h}^{j}+(1-s) \sum_{h} \sum_{j} \tau w_{h}^{j} L_{h}^{j}-J H \gamma_{0}-R^{0}\right] \\
& +\sum_{j=1}^{J} \mu^{j}\left[\sum_{h} \sum_{i} t_{i}^{j} x_{i h}^{j}+s^{j} \sum_{h} \sum_{k} \tau w_{h}^{k} L_{h}^{k}-\sum_{h} \gamma_{1 h}^{j} c_{h}^{j}-R^{j}\right]
\end{aligned}
$$

Differentiating $\tilde{L}$ with respect to $\tau$, setting equal to zero, and re-arranging, we obtain

$$
\begin{gathered}
\sum_{j} \sum_{h} w_{h}^{j} L_{h}^{j}\left[b_{h}^{j}-\tilde{s}+\frac{\tau w_{h}^{j} S_{L L, h}^{j}}{L_{h}^{j}}\left\{\tilde{s}+\left(\frac{1-\tau}{\tau}\right) \sum_{i} \tilde{t}_{i}^{j} \frac{\delta x_{i h}^{j}}{\delta M_{h}^{j}}\right\}\right] \\
=(\tau-1) \sum_{j} \sum_{h} w_{h}^{j} L_{h}^{j}\left[w_{h}^{j} \sum_{i} \tilde{t}_{i}^{j} \frac{\delta x_{i h}^{j}}{\delta M_{h}^{j}} \frac{\delta L_{h}^{j}}{\delta M_{h}^{j}}\right]
\end{gathered}
$$

where

$$
\tilde{s}=(1-s)+\sum_{j}\left(\frac{\mu^{j}}{\lambda}\right) s^{j}
$$

and the net social marginal utitlity of income, augmented to incorporate resource transfer, is given as follows.

$$
b_{h}^{j}=\frac{\delta \psi}{\delta W^{j}} \frac{\beta_{h}^{j}}{\lambda}+\sum_{i} \tilde{t}_{i}^{j} \frac{\delta x_{i h}^{j}}{\delta M_{h}^{j}}+\tau \tilde{s} w_{h}^{j} \frac{\delta L_{h}^{j}}{\delta M_{h}^{j}}
$$

Note that the other symbols are as defined before. The reader can easily verify from $\tilde{L}$, given in equation (23) and the demogrant specification given by equations (3), (4), that the 'optimal' value of $\gamma_{0}$ implies that

$$
\sum_{j} \sum_{h}\left[\frac{\delta \psi}{\delta W^{j}} \frac{\beta_{h}^{j}}{\lambda}+\sum_{i} \tilde{t}_{i}^{j} \frac{\delta x_{i h}^{j}}{\delta M_{h}^{j}}+\tau \tilde{s} w_{h}^{j} \frac{\delta L_{h}^{j}}{\delta M_{h}^{j}}\right]=J H
$$

or, in other words,

$$
\bar{b}=1
$$

Proceeding on the same lines as before, and using (27), we obtain the following expression for $\tau$. 


$$
\begin{gathered}
\operatorname{Cov}(b, Z)+\sum_{j} \sum_{h} \sum_{i}\left[\frac{\delta x_{i h}^{j}}{\delta M_{h}^{j}} Z_{h}^{j} \in_{L L, h}^{j}+e_{i h}^{j} e_{L h}^{j} x_{i h}^{j}\right] \tilde{t}_{i}^{j} \\
+\operatorname{Cov}(b, Z)+\sum_{j} \sum_{h}\left[\sum_{i} \tilde{t}_{i}^{j} \frac{\delta x_{i h}^{j}}{\delta M_{h}^{j}}-\tilde{s}\right] Z_{h}^{j} \epsilon_{L L, h}^{j}+(1-\tilde{s}) \sum_{j} \sum_{h} Z_{h}^{j}
\end{gathered}
$$

Note that (28) extends (20) to the case of resource transfers and specialises to the latter if there are no resource transfers i.e. $s^{k}=s=0$, i.e., $\tilde{s}=1$. A sufficient condition for resource transfer to have no effect on the optimal income tax rate is, therefore,

$$
s=\sum_{j}\left(\frac{\mu^{j}}{\lambda}\right) s^{j}
$$

or, alternatively,

$$
\lambda=\sum_{j}\left(\frac{s^{j}}{s}\right) \mu^{j} .
$$

We thus have the following proposition.

Proposition II: If, at the optimum, the marginal social cost of federal revenue is a weighted average of the marginal social costs of provincial revenue, with the weights given by the provinces' share of total resource transfer, then such transfers will have no effect on the optimal income tax rate.

To speculate on the nature of relationship between $\tilde{s}$ (i.e., implicitly, the $s^{k} s$ ) and $\tau$, let us consider the special case of no commodity taxes (i.e., $\tilde{t}_{i}^{j}=0$ ) and the social welfare function to be such that $\operatorname{Cov}(b, Z)=0 .(27)$, then, implies that

$$
\tau=\frac{(1-\tilde{s}) \sum_{j} \sum_{h} Z_{h}^{j}}{(1-\tilde{s}) \sum_{j} \sum_{h} Z_{h}^{j}-\tilde{s} \sum_{j} \sum_{h} Z_{h}^{j} \epsilon_{L L, h}^{j}}
$$

or, alternatively,

$$
\frac{1}{\tau}=1-\frac{\sum_{j} \sum_{h} Z_{h}^{j} \in_{L L, h}^{j}}{\left(\frac{1}{\tilde{s}}-1\right) \sum_{j} \sum_{h} Z_{h}^{j}}
$$


(30) implies that at the two extremes, $\tilde{s}=1$ (i.e. no resource transfer), and $\tilde{s}=0$, the optimal income tax rate will be zero and unity, respectively. (30) provides a convenient expression for the empirical calculation of $\tau$, and for an investigation of the impact of changing resource transfers on the estimated value of the optimal income tax rate in a federal set up.

\section{The Decentralised Federal Tax Model With Demogrants}

To allow provincial autonomy, we present a decentralised federal model where each tax authority acts independently taking as given the fiscal decisions made by the others. The federal government maximises the nation's SWF, given by equation (1), with respect to its own policy instruments only, subject to its resource constraints (eqn 5a), taking as given the provinces' instruments at their observed level. Similarly, each province $s$ maximises its residents' SWF, $W^{s}$ with respect to its own instruments, subject to its resource constraint (eqn. 5b), taking as given others instruments at their observed levels. To simplify the analysis, we consider the following linear demogrant scheme, where $\gamma_{0}$ is set by the Union, and $\gamma_{1}^{j}$ by the provinces.

$$
g_{h}^{j}=\gamma_{0}+\gamma_{1}^{j} c_{h}^{j}
$$

$$
j=1, \ldots, J
$$

In Lagrangean terms, therefore, the decentralised procedure involves separate maximisation of $\tilde{L}_{1}, L_{2}^{j}$ with respect to $\left(\gamma_{0}, \theta_{i}, \tau\right)$ and $\left(\gamma_{1}^{j}, t_{i}^{j}\right)$, where

$$
\begin{array}{r}
\tilde{L}_{1}=\psi(p, w, c, M)+\lambda\left[\sum_{j} \sum_{h} \sum_{i} \theta_{i} x_{i h}^{j}+\sum_{h} \sum_{j} \tau w_{h}^{j} L_{h}^{j}-J H \gamma_{0}-R^{0}\right] \\
L^{j}=W^{j}(p, w, c, M)+\mu^{j}\left[\sum_{h} t_{i}^{j} x_{i h}^{j}-\sum_{h} \gamma_{1}^{j} c_{h}^{j}-R^{j}\right] \\
j=1, \ldots, J .
\end{array}
$$

The consequence of optimal demogrants in the decentralised federal set up is as follows: 


$$
\begin{aligned}
0=\frac{\delta \tilde{L}}{\delta \gamma_{0}} & =\sum_{j} \sum_{h} \frac{\delta \psi}{\delta W^{j}} \frac{\delta W^{j}}{\delta v_{h}^{j}} \frac{\delta v_{h}^{j}}{\delta M_{h}^{j}} \\
& +\lambda\left[\sum_{j} \sum_{h} \sum_{i} \theta_{i} \frac{\delta x_{i h}^{j}}{\delta M_{h}^{j}}+\tau \sum_{j} \sum_{h} w_{h}^{j} \frac{\delta L_{h}^{j}}{\delta M_{h}^{j}}-J H\right] \\
0=\frac{\delta L^{j}}{\delta \gamma_{1}^{j}} & =\sum_{h} \frac{\delta W^{j}}{\delta v_{h}^{j}} \frac{\delta v_{h}^{j}}{\delta M_{h}^{j}} c_{h}^{j} \\
& +\mu^{j}\left[\sum_{h} t_{i}^{j} \frac{\delta x_{i h}^{j}}{\delta M_{h}^{j}} c_{h}^{j}-\sum_{h} c_{h}^{j}\right]
\end{aligned}
$$

Let us define

$$
\begin{aligned}
& b_{1 h}^{j}=\frac{\delta \psi}{\delta W^{j}} \frac{\beta_{h}^{j}}{\lambda}+\sum_{i} \theta_{i} \frac{\delta x_{i h}^{j}}{\delta M_{h}^{j}}+\tau w_{h}^{j} \frac{\delta L_{h}^{j}}{\delta M_{h}^{j}} \\
& b_{2 h}^{j}=\frac{\beta_{h}^{j}}{\mu_{j}}+\sum_{i} t_{i}^{j} \frac{\delta x_{i h}^{j}}{\delta M_{h}^{j}} .
\end{aligned}
$$

Note that $b_{1 h}^{j}, b_{2 h}^{j}$ can be interpreted as the social marginal valuation of income net of federal and provincial commodity taxes, respectively, and expressed in terms of the corresponding Lagrangean multipliers $\left\{\lambda, \mu_{j}\right\}$ as numeraire. These extend the interpretation to $b_{h}^{j}$ in the centralised federal case seen earlier [equation (8)].

The first order conditions [equations (34), (35)] imply

$$
\bar{b}_{1} \equiv \frac{1}{J H} \sum_{j} \sum_{h} b_{1 h}^{j}=1
$$

and

$$
\sum_{h} \tilde{\phi}_{h}^{j} b_{2 h}^{j}=1
$$

$$
j=1, \ldots, J
$$

where

$$
\tilde{\phi}_{h}^{j}=\frac{c_{h}^{j}}{\sum_{h} c_{h}^{j}} .
$$

$(37 \mathrm{a}, \mathrm{b})$ together imply 


$$
\sum_{j} \sum_{h}\left[\frac{b_{1 h}^{j}}{H}-\tilde{\phi}_{h}^{j} b_{2 h}^{j}\right]=0
$$

(38) implies that if all households have an identical number of children, i.e. $\tilde{\phi}_{h}^{j}=\frac{1}{H}$, then

$$
\bar{b}_{1}=\bar{b}_{2}
$$

i.e. mean of the two net social marginal utilities of income will coincide. Equation (38) also suggests that the reason for the means to diverge is an unequal demographic distribution across households.

\section{Optimal Commodity Taxes Under Alternative Models of Fiscal Federalism}

The difference between the centralised and decentralised federal models is brought into sharp focus in the context of optimal commodity taxes which we have not discussed so far. In large federal countries, e.g. India, commodity taxes are an important source of revenue. We turn to this issue now.

In the centralised federal specification of Section II, optimal federal and provincial commodity taxes, i.e. optimal $\theta_{i}, t_{i}^{j}$ imply the following relationships. ${ }^{8 /}$

$$
\begin{aligned}
& \sum_{j} \sum_{i} \tilde{t}_{i}^{j} S_{i k h}^{j}=-\sum_{j} \sum_{h} \bar{x}_{k}^{j}+\sum_{j} \sum_{h} b_{h}^{j} x_{k h}^{j} \\
& \sum_{i} \tilde{t}_{i}^{j} \sum_{h} S_{i k h}^{j}=-\frac{\mu^{j}}{\lambda} H \bar{x}_{k}^{j}+\sum_{h} b_{h}^{j} x_{k h}^{j}
\end{aligned}
$$$$
j=1, \ldots, J
$$

where $S_{i k h}^{j}$ is the Slutsky price response of individual $h$ in province $j$. Substituting (41) in (40) we obtain after some re-arrangement the following relationship between the mean consumption levels in the $J$ provinces.

$$
\sum_{j}\left(1-\frac{\mu^{j}}{\lambda}\right) \bar{x}_{k}^{j}=0
$$

$$
k=1, \ldots, n \text {. }
$$

Since $\bar{x}_{k}^{j} \nless 0,(42)$ implies that $\lambda$ must lie between $\mu^{j}(\min )$ and $\mu^{j}(\max )$. We, thus, have the following result. 
Proposition III: In the centralised federal specification, if federal and provincial commodity taxes are set optimally, then relationship (42) between the mean quantities demanded in the provinces must be satisfied, and the marginal social cost of federal revenue must lie between the minimum and maximum values of the marginal social cost of raising revenue in the provinces.

As a corollary of the above proposition, it follows that the case of identical marginal costs (i.e. $\mu^{j}=\lambda$ for all $j$ ) is consistent with optimal federal and provincial commodity taxes.

In contrast to the centralised model, the first order conditions for optimal commodity taxes in the decentralised model imply the following.

$$
\begin{gathered}
\sum_{j} \sum_{h} b_{1 h}^{j} x_{k h}^{j}=\sum_{j} \sum_{h}\left(x_{k h}^{j}+\sum_{i} \theta_{i} S_{i k h}^{j}\right) \\
\sum_{h} b_{2 h}^{j} x_{k h}^{j}=\sum_{h}\left(x_{k h}^{j}+\sum_{i} t_{i}^{j} S_{i k h}^{j}\right)
\end{gathered}
$$

$$
j=1, \ldots, J
$$

$(43,44)$ together imply the following relationship between federal and provincial commodity taxes.

$$
\sum_{j} \sum_{h}\left(b_{1 h}^{j}-b_{2 h}^{j}\right) x_{k h}^{j}=\sum_{j} \sum_{i} \sum_{h}\left(\theta_{i}-t_{i}^{j}\right) S_{i k h}^{j}
$$

(45) implies that equality between the two net social marginal utilities (i.e.

$\left.b_{1 h}^{j}=b_{2 h}^{j}\right)$ is consistent with equality between federal and provincial commodity taxes (i.e. $\theta_{i}=t_{i}^{j}$ ). A comparison of equations (42), (45) suggests that Proposition III is unlikely to hold in the decentralised case. This is confirmed by the empirical evidence for India to which we now turn.

Optimal commodity taxes for India, which has a federal tax structure, were calculated using a modification of the algorithm proposed in Murty and Ray (1989). The tax calculations were based on LES demand parameter estimates. Estimates of federal and provincial optimal commodity taxes, for a nine commodity disaggregation of consumer expenditure, under both the federal variants have been calculated for all the fifteen major provinces in India and reported in Murty and Ray (1990). Table 1 presents the estimates for the provinces of Bihar and Andhra Pradesh. The analysis of this paper suggests that optimal taxes and demogrants will depend on, among others, the specification of the social welfare function. In empirical work, it is common to 
vary the social welfare function specification through changes in the assumed value of the 'inequality aversion' parameter, $\epsilon$. To save space, we report here only the optimal tax estimates corresponding to a particular level of 'inequality aversion' $(\epsilon=0.5)$. The detailed results, which are available upon request, show that the taxes vary significantly with $\in$ in a manner consistent with the latter's economic interpretation [see, also, Ray (1986), Murty and Ray (1989)]. The results, presented in Table 1, establish sensitivity of optimal taxes to federal specification. They further confirm that, unlike in the fully co-ordinated case, under non cooperative behaviour, the shadow price of federal revenue need not lie between the minimum and maximum values of the shadow price of revenue of the constituent provinces of the federal Union. The tax estimates underline the importance of fiscal federalism in the study of optimal taxation.

The discussion in Section III has already pointed to the likely impact of allowing: resource transfer from the Union to the provinces on the optimal income tax rate in the centralised federal State. Table 2 provides illustrative empirical evidence, for India and its provinces of Bihar and Andhra Pradesh, on the sensitivity of optimal commodity taxes to alternative assumptions about resource transfers. The tax magnitudes, though not the estimates of the resource cost parameters $\left(\lambda, \mu^{1}, \mu^{2}\right)$ show considerable variation especially at high levels of $s$. The changes are mostly monotonic, though there are some interesting differences, in the direction of variation, between the optimal commodity taxes of the two provinces.

\section{Concluding Remarks}

This paper attempts to provide a framework for the simultaneous calculation of optimal income and commodity taxes in a federal framework with demogrants. The optimal income tax rate is shown to depend on a range of demographic and economic variables, including commodity taxes, household composition, the shadow welfare cost of federal and provincial revenue, the compensated wage elasticity of labour and the income elasticities of demand of the various items of consumption. The paper: presents alternative models of fiscal federalism, and examines their implications for optimal demogrants and commodity taxes. The analytical discussion and illustrative empirical evidence for India both confirm that the optimal tax rules and magnitudes are likely to be quite sensitive to federal specification, and to assumptions aobut resource transfer between the federal government and the provincial authorities. The large differences between the estimated magnitudes of optimal federal and provincial commodity taxes suggest that it may be misleading to assume, as many studies do, a. single tax setting authority in the context of large federal countries such as India. 


\section{Optimal Commodity Taxes under Alternative}

Federal Models ${ }^{(a)}(\epsilon=0.5)$

\begin{tabular}{|c|c|c|c|c|c|c|}
\hline Commodites & \multicolumn{3}{|c|}{ Centralised } & \multicolumn{3}{|c|}{ Decentralised } \\
\hline & $\theta_{i}$ & $t_{i}^{1}$ & $t_{i}^{2}$ & $\theta_{i}$ & $t_{i}^{1}$ & $t_{i}^{2}$ \\
\hline 1. Cererals & .048 & .070 & .143 & .011 & .032 & .109 \\
\hline 2. Milk and & .092 & .113 & .192 & .102 & .103 & .196 \\
\hline Milk Products & & & & & & \\
\hline 3. Edible Oil & .082 & .097 & .181 & .081 & .087 & .176 \\
\hline 4. Meat, Fish & .090 & .099 & .185 & .092 & .095 & .186 \\
\hline and Eggs & & & & & & \\
\hline 5. Sugar & .081 & .102 & .184 & .080 & .086 & .175 \\
\hline 6. Other Food & .087 & .103 & .182 & .088 & .092 & .182 \\
\hline 7. Clothing & .102 & .111 & .203 & .113 & .109 & .204 \\
\hline 8. Fuel and Light & .074 & .095 & .171 & .065 & .074 & .160 \\
\hline \multirow[t]{3}{*}{ 9. Other Non-Food } & .097 & .115 & .193 & .107 & .106 & .200 \\
\hline & $\lambda$ & $\mu(\min$ & $\mu(\max )$ & $\lambda$ & $\mu(\min )$ & $\mu(\max )$ \\
\hline & .644 & .606 & .712 & .541 & .551 & .664 \\
\hline
\end{tabular}

(a) Province 1 is Bihar, Province 2 is Andhra Pradesh 
Optimal Commodity Taxes in the Centralised Federal Model Under Alternative Assumptions about

Resource Transfer ${ }^{(a)}(\epsilon=0.5)$

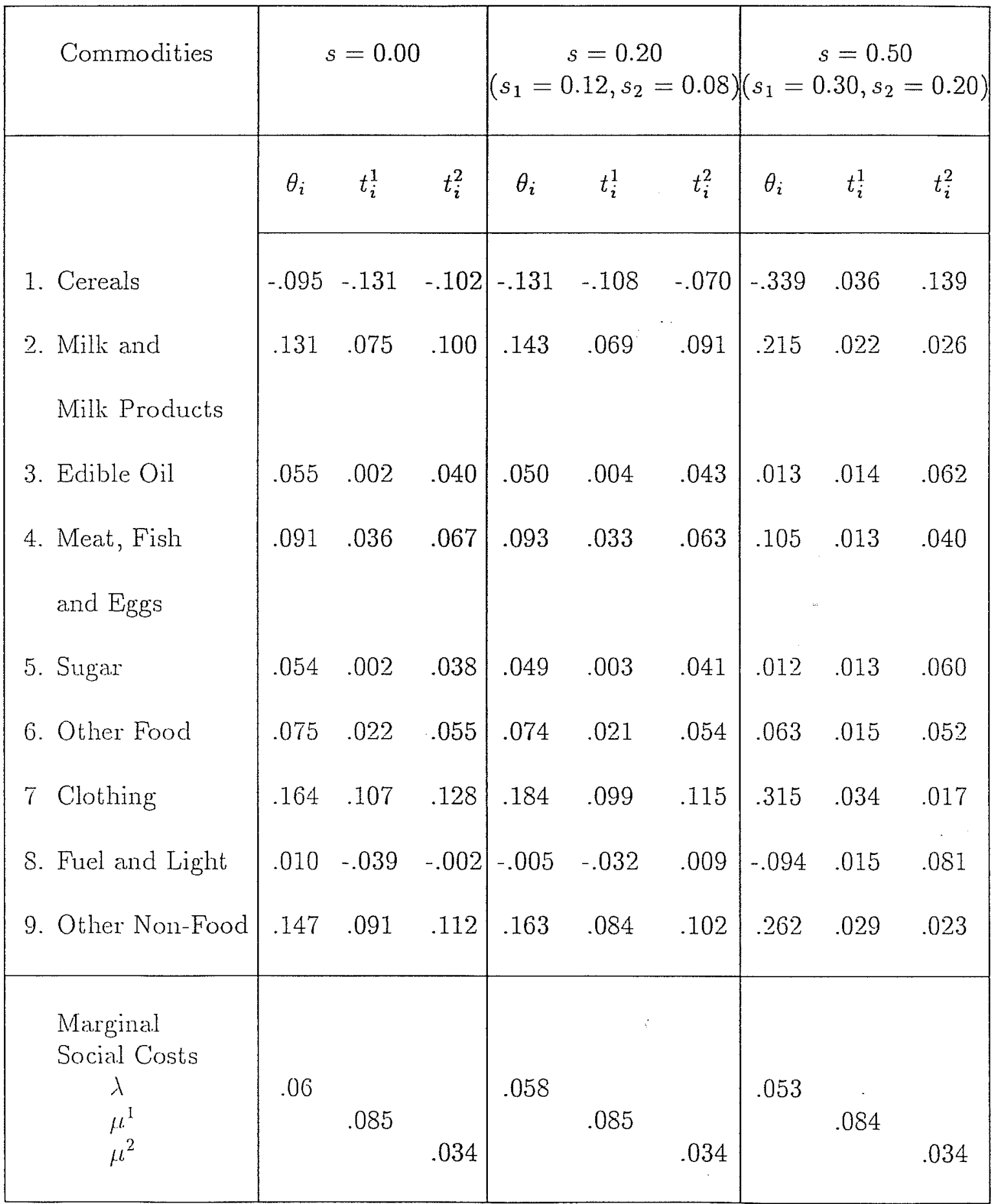

(a) The above estimates correspond to $\epsilon=2.0$. 


\section{FOOTNOTES}

1/ See Atkinson and Stiglitz (1980) and, more recently, Slemrod (1990) for a review.

2/ This is true for India - see Gulati and George (1988) for a recent description of federal financial relations in India.

3/ To keep the analysis simple, we consider only wage income and rule out, for example, capital income which involves intertemporal considerations.

4/ $c_{h}^{j}$ could be viewed, more generally, as a vector of demographic variables.

5/ $M_{h}^{j}$ is, therefore, also the aggregate household expenditure, since wage income is the only source of income, and savings is ruled out in this paper.

6/ The demogrant scheme $g_{h}^{j}$, given by $(3),(4)$ generalises that in the unitary tax model of Ray (1988) in allowing regional differences and possible non linearities in child subsidy via the parameter $\tilde{\gamma}_{1}^{j}$

T/ Note from (3), that differentiation with respect to $\gamma_{0}$ and $M_{h}$ are, formally, equivalent.

8/ See Murty and Ray (1990) for details of derivation. 


\section{References}

Arnott, R and R. Grieson (1981) 'Optimal Fiscal Policy for a State or Local Government', Journal of Urban Economics, 9, pp. 23-48.

Atkinson, A.B. and J.E. Stiglitz (1980) Lectures on Public Economics, Mc Graw Hill, New York.

Barten, A.P. (1964) 'Family composition, prices and expenditure patterns' in P.E. Hart, G. Mills and J.K. Whittaker (eds.), Econometric Analysis for National Economic Planning, Butterworth: London.

Diamond, P.A. (1975) 'A many-person Ramsey tax rule' Journal of Public Economics, 4, pp. 335-342.

Dixit, A.K. and A. Sandmo (1977) 'Some simplified formulae for optimal income taxation', Scandinavian Journal of Economics, 79, pp. 417-423.

Gordon, R.H. (1983) 'An optimal taxation approach to fiscal federalism', Quarterly Journal of Economics, pp. 567-586.

Gulati, I.S. and K.K. George (1988) Essays in Federal Financial Relations, Oxford and IBH Publishing Co, New Delhi.

Mintz, J. and H. Tulkens (1986) 'Commodity Tax Competition between Member States of a Federation: Equilibrium and Efficiency', Journal of Public Economics, 29, pp. $133-172$.

Mirrlees, J.A. (1971) 'An Exploration in the Theory of Optimal Income Taxation', Review of Economic Studies, 38, pp. 175-208.

Murty, M.N. and R. Ray (1989) 'A Computational Procedure for Calculating Optimal Commodity Taxes with Illustrative Evidence from India Budget Data', Scandimavian Journal of Economics, 91(4), pp. 655-670.

Murty, M.N. and R. Ray (1990) 'Fiscal Federalism and Optimal Commodity Taxes: a comparison of Centralised and Decentralised Decisions', Institute of Economic Growth, Delhi, Working Paper No. E/147/90.

Oates, W.E, (1990) 'Public Finance with Several Levels of Government: Theories and Reflections', Paper presented at 46th Congress of International Institute of Public Finance, Brussels, 27-30 August, 1990. 
Pollak, R.A. and T.J. Wales (1981) 'Demographic variables in demand analysis', Econometrica, 49, pp. 1533-1552.

Ray, R. (1986) 'Sensitivity of 'optimal' commodity tax rates to alternative demand functional forms: an econometric case study of India' Journal of Public Economics, 31, pp. 253-268.

Ray, R. (1988) 'Household composition and optimal commodity taxes: do demographic variables matter?', Journal of Population Economics, 1, pp. 213-224.

Slemrod, J. (1990) 'Optimal Taxation and Optimal Tax Systems', Journal of Economic Perspectives, 4(1), pp. 157-178.

Stern, N.H. (1976) 'On the Specification of Models of Optimum Income Taxation', Journal of Public Economics, 6, pp. 123-162.

Tuomala, M. (1984) 'On the optimal income taxation: some further numerical results', Journal of Public Economics, 23, pp. 351-366.

Wildasin, D.E. (1984) 'The Welfare Effects of Inter-governmental grants in an economy with distortionary local taxes', Journal of Public Economics, 25, pp. 103-125. 